\title{
O MITO NAS ENÉADAS DE PLOTINO
}

Reinholdo Aloysio Ullmann*

SÍNTESE - Em sua obra, Plotino recorre constantemente aos antigos, porquanto crê neles encontrar-se a verdade. Também não desconhece os mitos que lera nas obras de Platão. Interpreta-os metafísica e eticamente. Neste pequeno artigo, entende-se por mito "algo que alude a", "algo que indica", "algo que metaforiza". Três tipos de mitos são aqui apresentados brevemente: mitos da mitologia olímpica, mitos da escatalogia órfica e mitos filosóficos (mito da palavra e do silêncio). Em todos eles, percebe-se o esforço de Plotino por mostrar que o mito tenta exprimir o que a palavra não logra explicar, atingindo as fronteiras do silêncio e do inefável. $\mathrm{O}$ artigo concluí com o mito do silêncio, na união com o Uno, sem palavras.
ABSTRACT - In the Enneadae Plotinus constantly quotes the ancient philosophers, mainly Plato, then he thinks that they represent the truth. He also knows the myths and makes of them a metaphysical and ethical exegesis. In the present article, myth means "something that refers to", "that indicates", "that is a signal to". Three kinds of myths are here briefly exposed: myths of the Olympic mythology, myths of the Orphic eschatology and philosophical myths (myth of the word and silence). In all them Plotinus tries to express the higher level of meaning hidden in the myths, attaining the frontiers of the absolute silence, by the hênôsis with the One.

Embora se caracterize por um estilo hermético, destituido de floreios, Plotino não foi insensivel à linguagem do mito, porta-voz do pensamento. Porém, à maneira de Platão, ele demitiza o mito, "purificando-o dos elementos fantásticos, para conservar os caracteres alusivos e intuitivos" (Paviani, p. 61). Nesse sentido, podemos concordar com Porfírio em que o autor das Enéadas traz a marca de um filósofo "original" (Vita, 14, 15), por fazer uma exegese própria dos mitos encontradiços em Platão, que serviu de fonte inspiradora ou fio condutor do pensamento plotiniano (cf. Charrue, p. 34). "Nossas teorias não são novas, nem são de hoje, mas foram pensadas há muito tempo, porém não desenvolvidas. Nossos arrazoados são a interpretação (= exegese) das opiniões antigas" (En. V, 1,8,11-15). Dos antigos, "o velho sábio grego", como denominavam Plotino os islâmicos medievais, cita Homero, Xenófanes, Hesíodo, Teognides, Arquíloco, Píndaro, Eurípides, e até Lucrécio. Não sabemos, no entanto, se Plotino havia lido todas as obras ou os fragmentos desses autores, ou se apenas extraía passagens deles encontradas em Platão ou em autores posteriores. Como quer que seja, quando Plotino emprega o verbo phêsí, via de regra há de entender-se que se trata de Platão.

* Pontificia Universidade Católica do Rio Grande do Sul, PUCRS.

\begin{tabular}{|l|l|l|l|l|l|}
\hline VERITAS & Porto Alegre & v. 41 & no 163 & Setembro 1996 & p. 383-389 \\
\hline
\end{tabular}


Dentre os vastos conhecimentos que armazenara na memória, não faitava a mitologia, a qual "contaminou" a maior parte dos filósofos antigos. Aliás, à época de Plotino, os mitos gregos, em Roma, já não tinham a vitalidade de outrora, porque, com a abertura das fronteiras romanas, a mitologia fora suplantada pelos cultos soteriológicos e misticos vindos do Oriente. Ademais, o cristianismo havia entrado em luta aberta contra a mitologia e a religião pagãs.

Plotino quer retornar às fontes antigas, razão por que cita os pálaioi. Melhores do que os contemporâneos, a autoridade dos antigos porvém do fato de se encontrarem mais próximos das origens, quando a filosofia não estava corrompida pela usura do tempo (cf. Charrue, p. 23). Entre todos, "Platão é mais exato (akribésteros) do que os outros" ( $E$ n. V, 1,8,25). Assim sendo, Plotino vive indiferente à efervescência da erudição do seu tempo e alheio às idéias religiosas circundantes. A única exceção representa o gnosticismo que ele verbera acremente, por desfigurar a doutrina de Platão, o qual é honrado com o apodo de divino - hò theios Plátôn (En. IV, 8,1,23-24).

Plotino não considerava o mito como história sagrada tida por verdadeira. Ao contrário, para ele o mito exprime em palavras concretas os raciocínios abstratos, como que pintando-os com imagens. Para atenuar a imagem do mito e indicar-lhe um sentido de "segundo grau", Plotino emprega muitas vezes o advérbio hoion, com o significado de "como se".

Mito, em sentido plotiniano, neste pequeno estudo, há que ser entendido como "algo que alude a outra coisa", "algo indicativo", "que metaforiza", "que alegoriza". A alusão metafórica procura fazer compreender o que as palavras não conseguem exprimir. Nessa relação entre o mito e o seu significado, predomina a diferença.

Para Plotino, o mito remete para além de si próprio, para outra realidade. Dois conceitos ele usa, a fim de designar o verdadeiro significado do mito: 1) na En. I, 6,8,11, ele diz: hôs mythos ainittetai, i. é, "como o mito diz veladamente"; 2) na En. IV, 3,14,14, referindo-se ao mito de Prometeu, usa o verbo sêmaínein, que quer dizer "significar", "indicar", "anunciar", "sinalizar". Na En. V, 1,7,34, retorna o verbo ainíttein, com o sentido de aludir; o mesmo verbo encontramo-lo na En. VI, 2,22, 1 e 14; e na En. VI, 8,19,14, temos o advérbio ainizeôn = alusivamente.

Feitas essas observações, podemos, agora, proceder a uma rápida visão sobre alguns mitos e sua exegese plotiniana.

Três tipos de mitos caracterizam as Enéadas: 1) mitos da mitologia olímpica; 2) mitos órficos; 3) mitos da palavra.

\section{1 - Mitos da mitologia olímpica}

Conhecedor da cultura grega, Plotino não poderia deixar de referir-se a Zeus, "pai dos deuses e dos homens", esculpido em mármore por Fídias. Essa estátua era admirada por todos, dada a perfeição de seus traços. "Assim Fídias criou o seu Zeus, sem se inspirar no mundo do sensível, mas o reproduziu como se lhe tivesse aparecido e como se o próprio Zeus houvera consentido em manifestar-se aos nossos olhos (En. V, 8,1,39-40): Nessa escultura, eternizou-se um momento de espiritualização e sublimação do mundo mitológico. Em contemplando-a, o homem sen- 
te-se enlevado, porque percebe, no sinal visivel e compreensivel, a dimensão do inteligível, do divino. Numa palavra, a estátua de Zeus exerce uma função anagógica. Na En. IV, 4,10,4, Plotino consigna que "Zeus é o principio que rege o universo". Esse princípio não é o Uno plotiniano, fonte originária de tudo que existe, mas representa, na trilogia dos Crônidas, a Alma do mundo, ou seja, a terceira hipóstase. O velho sábio grego também aqui abandona o universo do mito e propõe uma categoria filosófica, que se pode sintetizar como mythus quaerens philosophiam.

Valendo-se da trilogia dos Crônidas, i. é, da tríade antiqüíssima da teogonia de Hesíodo, Plotino imprime-lhe um novo significado: Uranos, Kronos e Zeus vão corresponder às três hipóstases das Enéadas. Urano é o Uno, o super-ser, o hén simplesmente; Kronos é a inteligência, o noús, o hèn pollá, ou mundo dos inteligiveis; Zeus equivale à Alma do mundo (hèn kai pollá), que desempenha a função de demiurgo. Ela é a fonte imediata da vida (Zeus=zôé). Plotino atribui-lhe a paternidade das almas individuais.

Outro mito, muito do gosto de Plotino, é o de Eros, que se caracteriza pela concórdia, contrariamente a Eris, símbolo da discórdia e desarmonia. Vale a pena aduzir o que encontramos na En. VI, 9,9,24-31: "Que o Bem (=Uno) está lá em cima prova-o também o amor, que é congênito à alma (humana) (...). Sendo, porém, algo diverso de Deus, e, contudo, proveniente dele, a alma, por necessidade (ex anánkês) é enamorada dele e, enquanto está voltada para o alto, está repleta de amor celeste, ao passo que, voltando-se para as coisas daqui, torna-se vulgar. Voltada para 0 alto, a alma é uma Afrodite celeste; voltada para as coisas daqui, torna-se uma Afrodite semelhante a uma galanteadora. Toda alma é uma Afrodite". Plotino reduz o mito à sua simplicidade primigênia, elevando-o a categoria metafísica e moral. Purificado de ressaibos míticos, Eros nada mais é do que o desejo de Deus, em luta constante contra o sensualismo tendente aos gozos deste mundo. Eros, para Plotino, representa o eu mais alto, que procura guiar o homem e a história rumo à vida verdadeira do espírito.

\section{2 - Mitos órficos}

Fiel à sua convicção de que a autoridade dos antigos sinonimiza, pura e simplesmente, com a verdade (cf. En. II, 9,6,1.45; En. III, 7,1,1. 8-13; III, 7,7, 1.12), Plotino demonstra à saciedade que ele tem um animus antiquus. Nos antigos bebe-se a água da própria fonte. Na En. II, 9,6,37-44, lemos: "(...) não ofendamos os homens divinos (theíous ándras), mas acolhamos benevolamente as suas idéias, pois eles são mais velhos do que nós; recebamos deles o que dizem de belo, a imortalidade da alma, o mundo inteligivel, o primeiro Deus, a necessidade de a alma fugir do corpo (...)". Isso, sem dúvida, constitui uma homenagem respeitosa aos que contribuíram para descobrir a verdade. Contrasta esse tratamento respeitoso aos antigos com a recriminação dos contemporâneos, i. é, dos gnósticos: "Esses inventam todas essas coisas, como se jamais tivessem tido contato com a antiga cultura helênica (...); estão fora da verdade" (En. II, 9,6-10).

Em que sentido Plotino e órfico? O texto da En. II, 9,6,37-44 nos dá a pista para duas idéias: a imortalidade da alma e a fuga do corpo. Ademais, o mito de Orfeu fez com que Plotino valorizasse a música como elemento de elevação do es- 
pirito ao Uno. Também a ascese órfico-pitagórica corroborou-lhe a idéia da purificação interior pela virtude e, máxime, pela aphaírêsis, i. é, abstração e renúncia às coisas mundanas. Por fim, não se pode esquecer que a palingenesia é de inspiração órfica, como o é o dualismo corpo-alma. Na En. IV, 4,45, Plotino deixa entrever o mito pitagórico do inferno. Inferno mesmo é a idéia das punições dos maus, que nos faz lembrar um processus in infinitum: "(...) houve um tempo em que se praticava o que se sofre agora. Aquele que mata sua mãe, renascerá mulher, a fim de ser morto por seu filho. E o violentador renascerá mulher, para ser violentado" (En. III, 2,13,11-15).

Vimos, até agora, como Plotino vê os mitos referentes ao Olimpo e ao orfismo. A par desses, ele trata de outros, que faziam parte da imemorial tradição popular. Dentre eles, cabe citar quatro: o mito de Glauco, o de Narciso, o de Ulisses e o de Linceo.

A alma que peca e se recobre de mal Plotino compara-a ao deus marinho Glauco, todo encoberto de algas e conchas as quais o tornam irreconhecível. E cita Platão: "Nós vimos a alma como aqueles que vêem o deus marinho Glauco" (En.. I, 1,12,13).

Muito conhecido era o mito de Narciso, com o qual Plotino ilustra a vaidade humana: "Se alguém corresse ao encontro da beleza dos corpos, para prender-se a eles, como se foram realidade, ele seria semelhante a quem quisesse agarrar-se à própria imagem na água - como, segundo me parece, um certo mito o pretende mostrar - e, tendo-se curvado demais sobre a torrente, desaparece. Do mesmo modo, aquele que tende à beleza dos corpos, não com o corpo, mas com a alma, cairá nas profundezas tenebrosas e horriveis e pemanecerá no Hades, cego companheiro da sombra" (En. I,6,8,10-16). Que bela interpretação a de Plotino! Narciso é o jovenzinho enamorado de si, da sua imagem, do seu nada. Sua falsa e aparente auto-identidade é-lhe a desgraça.

A Narciso Plotino opõe a figura de Ulisses, desejoso de voltar à pátria. Ulisses é o símbolo daqueles que sabem pôr em prática a aphairêsis, a abstração das coisas do mundo cá debaixo. Simboliza os que não se deixam fascinar pela beleza aparente das Circes e Calipsos, mas querem fugir para a cara pátria: "Fujamos, pois, para a cara pátria! Este é o conselho mais verdadeiro que se pode dar" (En. I, 6,8,16-17). Que pátria é essa? "É aquela de onde vimos e lá em cima está nosso Pai" (ibidem). O Pai é o Uno (cf. Beierwaltes, p. 101).

Para empreender a viagem de retorno ao Uno (epistrophê), "é mister abandonar todas as coisas e não mais olhá-las; porém, mudando a vista corpórea por outra, despertar aquela faculdade que todos possuem, mas que poucos se esforçam por alcançar" (En. I, 6,8,25-27). Essa fuga, no entanto, não é solipsismo ou estratégica retirada "monástica" e, sim, a preocupação com as coisas do alto, do espírito.

A fim de tornar mais concreta a idéia da visão do espírito voltado às coisas imateriais, Plotino recorre ao mito do argonauta Linceo, o qual, com sua vista, "como se narra, enxergava até o interior das vísceras da Terra (eísô tês gês)". Para Linceo, não existe obstáculo; ele simboliza a mais elevada vida do espírito na contemplação do Uno. "Este mito refere-se aos olhos da inteligência" (En. V, 8,4,26).

A título de nota, vale a pena aludir à interpretação dada por Plotino ao mito da caverna. Eis o texto: "É como se alguns, que passassem a vida inteira a dormir, 
julgassem real e evidente o que lhes aparece em seus sonhos; e, se alguém os acordasse, não acreditariam no que vêem com os olhos abertos e tornariam a dormir" (En. V. 5,11,19-22). Plotino sustenta que a verdadeira realidade está "lá em cima", no mundo inefável do "Uno, que é o Bem" (En. V; $5,13,1)$. Até à pátria o filósofo renuncia por amor a valores mais altos (cf. En. V, 8,6,17).

\section{3 - O mito da palavra}

Se o mito "expressa aquilo que a argumentação lógica não pode dizer" (Paviani, p. 59), procurando desvelar o velado, logramos afirmar que a palavra humana em si também é mito, porque, ao mesmo tempo que revela (des-vela) algo, ela também o oculta. A palavra semelha um oráculo, "que não diz, nem oculta, mas indica" (Heráclito, fr. 93).

Ao escrever, Plotino atentava mais para o sentido do que para as palavras: "Era conciso, denso de pensamentos, breve, mais rico de idéias do que de palavras, e escrevia sob o dominio da inspiração e da paixão" (Vita, 14). E na Vita, 8, consta: "(...) ele se atinha somente ao sentido (mónon tou nou echómenos - )". A tradução de nous por "sentido" é exata, porquanto a expressão katà tòn noun significa "conforme o sentido".

Já que falamos em nous das palavras, é interessante aduzir a famosa Platonópolis, da qual nos fala Porfírio, na Vita, 12,1-12, cujo resumo é este: Plotino desejava fundar uma cidade na Campânia; os seus habitantes deveriam pautar-se pelas leis de Platão. Chamar-se-ia Platonópolis, em homenagem ao fundador da Academia. Lá queria viver Plotino com seus amigos: Porém, alguns senadores, por inveja, mesquinhez ou outro motivo perverso, se opuseram ao plano. E tudo gorou. O padre Vincenzo Cilento, estudioso de Plotino, afirma sem rebuços: "Platonópolis é um mito" (Les sources de Plotin, p. 270), considerando-a um símbolo, como a civitas de Santo Agostinho (ibid., p. 320). Que dizer a isso? A afirmação de Cilento parece um tanto ousada, porquanto a oposição de alguns senadores à idéia de Plotino deve, assim pensamos, ser tomada como um fato histórico verídico, e não como metáfora. É até possível admitir-se que Plotino quisesse fundar uma espécie de mosteiro pagão, para recolhimento espiritual de quem desejasse progredir na virtude e na contemplação do Uno.

Feita essa digressão, retornemos ao mito da palavra.

Plotino não desconhecia a falácia da linguagem humana e da sua também. Por isso, constantemente se esforçava por tentar corrigir o pensamento, introduzindo o advérbio hoion, conforme já foi dito. Essa palavrinha tem o condão de transportar o pensamento a novos patamares, até às fronteiras do indizivel, onde impera o reino do silêncio, na imutabilidade da solidão do Uno.

Nem é demasiada afoiteza dizermos que Plotino criou uma "filosofia do silêncio". O silêncio misterioso envolve a sua origem e o nome dos pais (cf. Vita, 1,2-5). "Ele (Plotino) não confiou a ninguém nem o mês em que nasceu, nem o dia de seu nascimento (...)" (Vita, 2,38-39).

A máxima apologia do silêncio temo-la no fim da última Enéada: "Esta é a vida dos deuses e dos homens divinos e felizes: separação das demais coisas cá debaixo, vida que não mais se compraz com as coisas terrenas - fuga do solitário 
para o solitário" (VI, 9,11,49-51). "(..) ali a alma entra silenciosamente na solidão, num estado que não conhece turbação" (VI, 9,11,13-14). É a paz perfeita, no gozo do êxtase, na redução à máxima simpliciđade (háplôsis), a qual sinonimiza com assemelhação a Deus, conforme lemos em En. I, 2 (19), 1,3-4: "A fuga do mundo consiste em tornar-se semelhante a Deus. Consoante o testemunho de Porfírio, quatro vezes, enquanto esteve com Plotino, este teve a experiência mística da união com - Uno (Vita, 23,16-18). O verbo, para exprimir a união com o Uno, é enôthênai (En. VI, 9,9,34). Essa hênôsis não é anulação, dissolução ou aniquilamento da alma, pois consta claramente: "Aqui o homem pode ver o Uno (=Bem) e a si mesmo (...)" (En. VI, 9,9, 56-57). Atinge-se, assim, o ponto pinacular da filosofia de Plotino fuga do solitário para o solitário; fuga para o império metafísico do silêncio, do êxtase, da contemplação da fonte da Beleza.

Corajosamente devemos afirmar estarmos na presença de um místico pagão. Isso é contraditório? Não. Plotino sempre se esmerou por buscar as coisas eternas, por praticar as virtudes, por manter-se puro. Por que não poderia ter a graça da união mística já nesta vida?

Assinalamos que Plotino pregou a "fuga do mundo" e a aphairêsis. Mas, a par dessa ética da fuga, o velho sábio grego também pregou a ética do dom, "anunciando aos seus ouvintes a união com o Uno" (En. VI, 9, 7, 23). Aliás, podemos dizer que todas as Enéadas representam um verdadeiro Evangelho para aquele tempo e para as épocas posteriores, haja vista seu influxo exercido na história da mística medieval.

Em suma, a háplôsis e a hênôsis representam uma incursão consciente do homem ao interior da alma, em obediência ao áphele pánta (abstrai de tudo) (En. V, $3,17,38$ ). Essas palavras têm a força de um imperativo categórico.

Concluamos. Neste pequeno estudo, tentamos esclarecer que o mito, para Plotino, encerra um potencial oculto. Desvelado, ele traz nova informação na qual resplandecem luzes não antes suspeitadas. No mito, uma imagem leva a outra, mais esclarecedora, mais diáfana e mais densa de significado. Dir-se-ia que o desvelamento do mito constitui uma superação do vulgar e o encontro do seu fundamento filosófico. Dessarte, o mito se converte em palavra criadora de uma nova realidade, seja metafísica, seja ética.

Por fim, cabe indagar por que Plotino se vale tanto dos mitos para explicações filosóficas. A resposta pode ser esta: 1) por ter feito a exegese de Platão, no qual abundam os mitos; 2) no contexto histórico da época, Plotino fez uma tentativa de revitalizar o significado dos mitos, em face da religião cristã em expansão; 3) o mito, para o velho sábio grego, tem função educativa, quando se transporta o seu significado para o supratemporal. O mito evoca valores humanos e divinos, desperta a saudade da verdadeira pátria, da solidão silenciosa, onđe cessa o pensamento discursivo. Aqui, sem o invólucro da palavra, o pensamento se desnuda diante do esplendor ofuscante do Uno. Era esse o escopo da vida de Plotino. 


\section{Referências bibliográficas}

BEIERWALTES, Werner. Pensare I'Uno. Milano: Vita e Pensiero, 1991.

CHARRUE, Jean-Michel. Plotin - lecteur de Platon. 3. ed. Paris: Société D'Édition "Les Belles Lettres", 1993.

CLENTO, V. Mito e poesia nelle Enneadi di Plotino. In: Les sources de Plotin. Vandoeuvres - Genève, 1957, p. 245-323.

HERÁCLITO. Fragmentos.

PAVIANI, Jayme. Escrita e Linguagem em Platão. Porto Alegre: EDIPUCRS, 1993.

PLOTINO, Enneadi - PORFIRIO, Vita di Plotino. 3. ed. Milano: Rusconi, 1992. 